\title{
Breaking the Paradigm
}

\author{
Marvin L. Birnbaum, MD, PhD
}

While preparing this piece, I confidently looked for the word "research" in the medical dictionaries (Stedman's, Dorland's), and much to my surprise, it was not to be found. Thus, it must be that research has no meaning that is specific to medicine. I was able to find the word in both the Webster and American Heritage dictionaries. The definitions read:

Research-to investigate thoroughly; careful or diligent search; studious inquiry or examination; investigation or [emphasis added] experimentation aimed at discovery or interpretation of the facts; revision of accepted theories or laws in light of new facts, or practical application of such new or revised theories or laws. ${ }^{1}$ Scholarly or scientific investigation or inquiry; to study thoroughly. ${ }^{2}$

No matter where I looked, I was unable to find any definition of research that supported the paradigm that medical research equals randomized, controlled experiments. Yet, it is this paradigm that continues to indicate respectability in medical research.

I wondered if the paradigm that only randomized, controlled experiments constituted the only true science, and that any work other than this does not constitute "science." So, I searched for the definition of "science." I found several definitions in Dorland's Medical Dictionary:

Science-1) The observation, identification, description, and theoretical explanation of natural phenomena; 2) Such activity restricted to a class of natural phenomena; 3) Such activity applied to any class of phenomena; 4) Any methodological activity, discipline, or study; 5) Any activity that appears to require study and experience; 6) Knowledge, especially knowledge gained through experience. ${ }^{3}$

This "medical" definition does not support the paradigm, so I consulted the lay dictionaries:

Science-1) the systematic observation of natural phenomena for the purpose of discovering laws governing those phenomena; 2) the body of knowledge accumulated by such means. ${ }^{4}$ Science-1a) possession of knowledge as distinguished from ignorance and misunderstanding; 1b) knowledge obtained through study or practice; 2a) a department of systematized knowledge as an object of study; 3) knowledge covering general truths or the operation of general laws, especially as obtained and tested through the scientific method. ${ }^{5}$

Even these definitions do not support the paradigm, but seem to give substantial weight to using a systematic methodology to gain knowledge of truths. Certainly, then, the paradigm must be supported by the definition of the "scientific method." Again:

Scientific method-principles and procedures for the systematic pursuit of knowledge involving recognition and formulation of a problem, the collection of data through observation and experiment, and the formulation and testing of hypotheses. ${ }^{5}$ The total- ity of principles and processes regarded as characteristic of or necessary for scientific investigation, generally taken to include rules for concept formation, conduct of observations and experiments, and validation of hypotheses by observation or experiments. ${ }^{6}$

Even the definitions of the scientific method leave abundant room for the inclusion of other forms of research that are outside of the current paradigm as valid and consistent with the scientific methodology. The definitions of science and the scientific method include observations as well as experiments and the formation of hypotheses as well as their testing through experimentation.

Dingwall, in commenting on health research, stated that, "One of the greatest methodological fallacies of the last half century...is the belief that science is a particular set of techniques; it is, rather, a state of mind, or attitude, and the organizational conditions which allow that attitude to be expressed." Mays and Pope note that:

In the health field-with its strong tradition of biomedical research using conventional quantitative, and often experimental methods-qualitative research is often criticized for lacking scientific rigor. To label an approach "unscientific" is peculiarly damning in an era when scientific knowledge is generally regarded as the highest form of knowing. The most commonly heard criticisms are, firstly, that qualitative research is merely an assembly of anecdote and personal impressions, strongly subject to personal bias; secondly, it is argued that qualitative research lacks reproducibilitythe research is so personal to the researcher that there is no guarantee that a different researcher would not come to radically different conclusions; and, finally, qualitative research is criticized for lacking generalizability. It is said that qualitative methods tend to generate large amounts of detailed information about a small number of settings. ${ }^{8}$

I do not know how the concept originated in medicine that only facts determined using randomized, controlled experimentation constitute good medical science, but it continues to pervade all of medicine. Certainly, randomized, controlled experiments do constitute the best method for relating cause and effect. Quasi-experimental methods, such as longitudinal studies, provide less evidence for relating cause and effect, but often are valid measures for what is being studied and have the advantage in assessing the effects of a change in process when there is little ability to find an identical service with which to compare. Hence, they are used frequently in the study of prehospital emergency medical services.

Other methods of investigation actually may have greater external and construct validity than does experimentation. ${ }^{8}$ Methodologies with high degrees of validity include qualitative, epidemiological, and evaluative research techniques. These methodologies incorporate surveys, interviews, focus 
groups and other consensus-producing methods, and case studies. Each of these techniques has optimal utility in finding answers to specific types of questions and for producing knowledge that is both valid and useful. ${ }^{8-14}$ Actually, the rigors of each of these methods are as severe as are those used in experimental research. The methodologies are well-defined and the answers and hypotheses they produce may have great relevance to medical practice. In fact, there could not be any hypothesis-testing research without preceding qualitative research used in the formation of the hypothesis.

Despite the fact that few of us have been trained in any methodologies other than those used for hypothesis testing, we all, knowingly or unknowingly, have utilized these other methods. We have used them in doing the background research for hypothesis development, we have used them in formulating board examination questions, we have participated in focus groups used extensively by the emergency medical services industry, we have developed position papers using group consensus methods when other forms of definitive data were lacking and have modified our practices in accordance with such consenses, we have reported cases that we believe have relevance to our work, and more. We have used these techniques and have believed in their results. But, our training did not allow us to recognize our use and involvement. Yet, when it comes to evaluating work accomplished using these methodologies, we summarily dismiss them as "non-scientific!"

We subject our research to peer review because all of us are not able to be expert in all of the valid methodologies used in research. Peers are chosen for review because such individuals are recognized as experts in the techniques used in the research, not only because they possess expertise in the content of the research. Review by our peers in the techniques used establishes the work as science before it is published. It is not appropriate to judge a work with the bias that the methodology is not scientific, but rather with the bias that the methodology has been reviewed by experts and that the experts agree that the methodology is solid for the area that has been studied and that appropriate conclusions are drawn from the research. This is the process we have selected to define our science; this is how we decide whether the research is valid.

It is time that we recognize other forms of research as valid and reproducible rather than condemning work on the basis of our limitations and misunderstanding. We must become open to a broader range of methodologies and recognize their utility and validity in answering certain questions. We must broaden our knowledge to embrace techniques other than the experimental methodology. It is incumbent upon training programs to include education espousing a broader scope of research and not continue to concentrate solely on quantitative, experimental methodologies. Recognizing that most of us do not understand and are not facile with techniques other than the experimental methods, Prehospital and Disaster Medicine will follow the path taken by the $B M J$ (formerly the British Medical Joumal) ${ }^{8-14}$ by publishing discussions on research techniques other than the experimental. These will be presented as continuing education with appropriate recognition for those who participate. The first of these discussions will be published in a supplement to the next issue, in which Drs. Noji, Pretto, and Ricci will discuss evaluation and epidemiological methods as applied to disaster research. Beginning with Volume 12, each issue will provide additional information and discussion of various qualitative methodologies as they apply to our science.

We must break the paradigm forced on us by those not knowledgeable in the merits of non-experimental methodologies or of the limitations imposed by experimental research designs. A scientist is "one learned in science, especially one active in some particular field of investigation." 3 We all are scientists, each with our own areas of expertise. But, experts often are limited to their respective areas of expertise. Without knowledge of other methodologies, we are blinded to the essence of our science. Discover the rigors of qualitative research, when and how to use these research techniques, incorporate them into your research efforts, broaden the scope and applicability of your research, and learn to appreciate important work of those who possess expertise in these valuable areas of medical research.

\section{References}

1. Webster's New Collegiate Dictionary, GC Merriman Co. 1974 p 984

2. The American Heritage Dictionary of the English Language, Morris W (ed) Houghton Mifflin Co. Boston 1980. p 1104.

3. Dorland's Illustrated Medical Dictionary, 27th ed., WB Saunders Co., Harcourt Brace Jovanovich Inc., Philadelphia, 1985. p 1494.

4. The American Heritage Dictionary of the English Language, Morris W (ed). Houghton Mifflin Co. Boston 1980. p 1162.

5. Webster's New Collegiate Dictionary, GC Merriman Co. 1974. p 1034.

6. Dorland's Illustrated Medical Dictionary, 27th Ed., WB Saunders Co., Harcourt Brace Jovanovich Inc., Philadelphia, 1985. p 1163.

7. Dingwall R: "Don't mind him-he's from Barcelona": Qualitative methods in health studies. In: Daly J, Willis $\mathrm{E}$ (eds). Researching Health Care: Designs, Dilemmas, Disciplines. London: Tavistock/Routledge. 1992. pp 161-175.

8. Mays N, Pope C: Rigour and qualitative research. $B M]$ 1995:311:109-112.

9. Pope C, Mays N: Reaching the parts other methods cannot reach: An introduction to qualitative methods in health and health services research. BMJ 1995;311:42-45.

10. Mays N, Pope C: Observational methods in health care settings. BMJ 1995;311:182-184.

11. Britten N: Qualitative interviews in medical research. $B M J$ 1995;311:251-253.

12. Kitzinger J: Introducing focus groups. BMJ 1995;311:299-302.

13. Jones J, Hunter D: Consensus methods for medical and health services research. $B M J 1995 ; 311: 376-380$.

14. Keen J, Packwood T: Case study evaluation. BMJ 1995;311:444-446. 